\title{
NEUROTOXICITY EFFECT IN CANCER REGIMENT CARBOPLATIN-PACLITAXEL
}

\author{
ANNISA DIYAN MEITASARI*, EM SUTRISNA, ZAKKY CHOLISOH
}

Department of Pharmacy, Politeknik Indonusa Surakarta and Muhammadiyah Surakarta University, Surakarta, Indonesia. Email: diyanmeitasari@poltekindonusa.ac.id

Received: 30 June 2021, Revised and Accepted: 09 September 2021

ABSTRACT

Objective: Side effects due to chemotherapy were frequently reported and some of them require immediate treatment. Cervical cancer, breast cancer, and ovarian cancer are types of cancer that are often found in Dr. Moewardi Surakarta Hospital and $45 \%$ of the three types of cancer used the chemotherapy regimen of carboplatin-paclitaxel. Carboplatin-paclitaxel was chosen because it is a regimen that has fewer side effects.

Methods: This study aims to identify the type of adverse drug reactions (ADRs) neurotoxicity, percentage, and severity, as well as to determine the risk factors for the occurrence of ADRs such as age, gender, type of cancer, number of cycles, length of stay, and types of comorbidities in cancer patients using carboplatin-paclitaxel therapy regimen in RSUD Dr. Moewardi Surakarta for the period September to December 2019. This study was an observational study with a cross-sectional design through prospective data searches. The inclusion criteria in this study were adult cancer patients on carboplatin-paclitaxel therapy who were willing to be research subjects.

Results: The incidences of ADRsin patients using the carboplatin-paclitaxel therapyregimen in this study were sensoryperipheral neuropathy (77.69\%); motor peripheral neuropathy (3.31\%); joint pain (53.72\%); and muscle weakness (37.19\%) The instrument to measure the severity in this study used common terminology criteria for adverse events with the results of ADRs with grade 1 (35.08\%), grade 2 (61.02), grade 3 (2.88\%), and at grades 4 and $5(0 \%)$. Risk factors for gender, age, length of stay, type of cancer, number of cycles, and comorbidities did not affect the incidence of neurotoxicity in cancer patients with the carboplatin-paclitaxel therapy regimen.

Keywords: Adverse drug reactions, Neuropathy, Sensory, Motor, Joint, Muscle, Carboplatin, Paclitaxel, Common terminology criteria for adverse events, Number of cycles.

(C) 2021 The Authors. Published by Innovare Academic Sciences Pvt Ltd. This is an open access article under the CC BY license (http://creativecommons.org/ licenses/by/4.0/] DOI: http://dx.doi.org/10.22159/ajpcr.2021v14i10.42929. Journal homepage: https://innovareacademics.in/journals/index.php/ajpcr

\section{INTRODUCTION}

Cancer is a disease characterized by continuously abnormal growth cells because cancer cells are lack or fail to respond to homeostatic mechanisms in controlling cell division [1]. Research at 185 countries in 2018, a total of 18.1 million patients were diagnosed with cancer and 9.6 million died [2]. Cancer is a disease that causes high mortality, so the development of cancer drugs is the priority. Standard antineoplastic therapies including cytotoxic chemotherapy have the risk of adverse events. New antineoplastics are increasing, so the diversity of adverse drug reactions (ADRs) is increasing. Factors that influence ADRs are antineoplastic types, frequency, ethnic diversity, and disease severity [3].

Carboplatin-paclitaxel is a chemotherapy regimen used for lung cancer, ovarian cancer, breast cancer, cervical cancer, and cancer of the digestive tract [4]. ADRs carboplatin-paclitaxel regimen in patients with ovarian cancer with percentage $>10 \%$ is edema, headache, insomnia, asthenia, fatigue, pain, back pain, alopecia, hypokalemia, dyspepsia, anorexia, constipation, diarrhea, nausea, vomiting, mucositis, stomatitis, anemia, granulocytopenia, leukopenia, neutropenia, thrombocytopenia, fever, infection, arthralgia, myalgia, motor neuropathy, sensory neuropathy, paresthesia, peripheral neuropathy, and dyspnea [5].

Adverse reactions carboplatin with incidence $>10 \%$ are pain, hyponatremia, hypomagnesemia, hypocalcemia, hypokalemia, nausea, vomiting, leukopenia, thrombocytopenia, anemia, neutropenia, increased SGOT and SGPT values, weakness, decreased creatinine clearance, and increased BUN values. Adverse reactions to paclitaxel whose incidence $>10 \%$ are edema, hypertension, fever, pain, dysesthesia, rash, pruritus, erythema, gastrointestinal disturbances, proteinuria, cough, and rhinitis [6]. Patient who uses paclitaxel cisplatin and paclitaxel carboplatin is decrease in hemoglobin, thrombocyte, as well as leukocyte values [7].

The carboplatin-paclitaxel regimen can be used for several types of cancer. Research of ADRs neurotoxicity carboplatin-paclitaxel does not find, so it is necessary to do research on this in patients who use the regimen of carboplatin-paclitaxel. This study can provide information about the type of neurotoxicity, percentage, and severity of patients who use carboplatin-paclitaxel at Dr. Moewardi Hospital Surakarta, with the hope of anticipating side effects during the treatment period so can increase quality of life patient's.

\section{METHODS}

This study used an observational study with a cross-sectional design through prospective data searches leading to a cohort through medical records of cancer patients who used the carboplatin-paclitaxel regimen at Dr. Moewardi Hospital Surakarta. Patients identified ADRs using common terminology criteria for adverse events (CTCAE) and Naranjo's instrument. The independent variable is age, gender, type of cancer, number of cycles, length of stay, and comorbidities. This research was conducted for 4 months, starting from September to December 2019 at RSUD Dr. Moewardi Surakarta. Samples were determined by consecutive sampling method with inclusion and exclusion criteria as follows:

\section{Inclusion criteria}

a. Adult cancer patient

b. Patient receiving Carboplatin-Paclitaxel regiment

c. Complete data about independent variables (gender, age, type of cancer, number of cycles, length of stay, and comorbidities)

d. Patients are willing to be research respondents, prove by signing informed consent. 


\section{Exclusion criteria}

a. Patients with HIV, tuberculosis, liver disorders, kidney disorders, mental disorders, and gastrointestinal disorders

b. Lost follow-up.

This analysis was used to analyze the relationship between independent variables (age, gender, type of cancer, number of cycles, length of hospitalization, and comorbidities) and dependent variables (sensory peripheral neuropathy, motor peripheral neuropathy, joint pain, and muscle weakness). Analysis data will use contingency coefficients if type data nominal versus nominal and will use Eta analysis when type data nominal versus numerical

\section{RESULTS AND DISCUSSION}

The number of patients who used carboplatin-paclitaxel therapy regimen in October-December is 121 patients and $100 \%$ female. All patients is female because in this hospital the carboplatin-paclitaxel regimen was used for chemotherapy in cervical cancer, ovarian cancer, and breast cancer. Women have a higher incidence of cancer, possibly because of differences in hormones, namely estrogen and progestin,

Table 1: Characteristics of patients using the paclitaxel-carboplatin regimen in cancer patients at Dr. Moewardi Hospital Surakarta

\begin{tabular}{|c|c|c|}
\hline Characteristics & Total $(n=121)$ & Percentage \\
\hline \multicolumn{3}{|l|}{ Gender } \\
\hline Women & 121 & 100 \\
\hline Man & 0 & 0 \\
\hline \multicolumn{3}{|l|}{ Age } \\
\hline $16-25$ & 1 & 0.8 \\
\hline $26-35$ & 2 & 1.6 \\
\hline $36-45$ & 19 & 15.7 \\
\hline $46-55$ & 43 & 35.5 \\
\hline $56-65$ & 43 & 35.5 \\
\hline$>65$ & 13 & 10.7 \\
\hline \multicolumn{3}{|l|}{ Ethnic } \\
\hline Java & 121 & 100 \\
\hline \multicolumn{3}{|l|}{ Cancer Type } \\
\hline Ovarian Cancer & 38 & 31.4 \\
\hline Cervical Cancer & 44 & 36.3 \\
\hline Breast Cancer & 39 & 32.2 \\
\hline \multicolumn{3}{|l|}{ Number of Cycle } \\
\hline 2 & 37 & 30.6 \\
\hline 3 & 32 & 26.4 \\
\hline 4 & 21 & 17.4 \\
\hline 5 & 17 & 14.0 \\
\hline 6 & 14 & 11.6 \\
\hline \multicolumn{3}{|l|}{ Length of Stay } \\
\hline 1 day & 43 & 35.5 \\
\hline 2 days & 60 & 49.6 \\
\hline 3 days & 18 & 14.9 \\
\hline \multicolumn{3}{|l|}{ Comorbidity } \\
\hline Without & 98 & 81.0 \\
\hline With & 23 & 19.0 \\
\hline Hypertension & 4 & 3.3 \\
\hline Diabetes Mellitus & 14 & 11.6 \\
\hline Hypertension+Diabetes Melllitus & 4 & 3.3 \\
\hline Hypertension+Diabetes & 1 & 0.8 \\
\hline Meliltus+Ashtma & & \\
\hline
\end{tabular}

which are found more in women. In addition, menopause is also a risk factor for cancer [8]. In this study, patients aged 46-65 years had a higher percentage. This is similar to research that there is a direct correlation between increasing age and levels of ADRs [9]. The complete data of characteristic sample are shown in Table 1.

Based on characteristic data patients who use carboplatin-paclitaxel are $31.4 \%$ ovarian cancer, $36.4 \%$ cervical cancer, and $32.2 \%$ breast cancer. Carboplatin-paclitaxel is the primary therapeutic regimen used in adjuvant therapy of all stages of ovarian cancer [5]. Carboplatinpaclitaxel is the first line of therapy for advanced breast cancer [10]. Therapy for cervical cancer varies according to the patient's condition, carboplatin-paclitaxel is used in the treatment of relapsed and metastatic cervical cancer [11]. One of the advantages of combination carboplatin-paclitaxel is less toxic than cisplatin and paclitaxel, but it is necessary to pay attention at platelet value, incidence of alopecia, and symptoms of neuropathy [12]. Another study said that the use of the carboplatin-paclitaxel combination had a higher success rate than the cisplatin-paclitaxel combination [13]. A total of 140 ADRs were reported from platinum analogs following treatment of different types of cancer in hospital. Most of the ADRs that happen to patient were observed in the age group of 40-60 years. Vomiting (27 ADRs) was commonly reported reaction. Among platinum analogs, cisplatin leads to 82 ADRs (58.57\%) followed by carboplatin with 53 ADRs (37.86\%) and least with oxaliplatin 5 ADRs (3.57\%) [14].

Carboplatin-paclitaxel therapy regimen in patients with ovarian cancer, cervical cancer, and breast cancer was used every 21 days for 6 cycles. In this study, patients who take second-cycle chemotherapy have the highest percentage. Patients with a higher number of cycles have a higher risk of experiencing ADRs [15].

In Table 2, sensory peripheral neuropathy (77.79\%) became the most common ADRs in the area of muscle and joint disorders, followed by joint pain $(53.72 \%)$, muscle weakness (37.19\%), and peripheral neuropathy motoric $(3.31 \%)$. Routine use of platinum agents such as oxaliplatin, cisplatin, and equal portions in combination with carboplatin-paclitaxel can cause long-term damage to peripheral sensors. Peripheral sensor ADRs occur in $30-40 \%$ of patients taking these agents. Paclitaxel which is a taxane class of drugs also triggers neuropathy [16]. Single paclitaxel therapy resulted in $9.52 \%$ experiencing muscle weakness [17]. Peripheral neuropathy was experienced in $46.6 \%$ of patients after chemotherapy with a carboplatin-paclitaxel regimen [18].

This study analyzed the relationship of risk factors to the incidence of peripheral neuropathy sensory, peripheral neuropathy motoric, arthralgia, and muscle weakness. The risk factors tested were gender, age, type of cancer, number of cycles, length of stay, and comorbidities. Bivariate analysis used contingency coefficients for risk factors cancer type and comorbidities. Bivariate analysis using Eta for risk factors length of stay, age, and the number of cycles. The results of all bivariate analyze is p-value $>0.05^{*}$ so it can be concluded that the risk factors gender, age, type of cancer, number of cycles, length of stay, and comorbidities have no effect on neurotoxicity due to carboplatin-paclitaxel. This is different from the study in Nepal which stated that older patient has a higher incidence of ADRs. The higher incidence of ADRs may be related to organ function which can result in low metabolic capacity and decreased drug excretion which can accumulate drugs in the body thereby increasing the risk of ADRs [19]. Patients without comorbidities, having hypertension, diabetes mellitus, hypertension+diabetes mellitus,

Table 2: Incident neurotoxicity and severity carboplatin-paclitaxel regiment

\begin{tabular}{|c|c|c|c|c|}
\hline ADRs & Incident $(n=121)(\%)$ & Grade 1 CTCAE (\%) & Grade 2 CTCAE (\%) & Grade 3 CTCAE (\%) \\
\hline Peripheral neuropathy sensory & $94(77.69)$ & $25(12.01)$ & $66(31.7)$ & $3(1.44)$ \\
\hline Peripheral neuropathy motoric & $4(3.31)$ & $3(1.44)$ & $1(0.48)$ & 0 \\
\hline Arthalgia & $65(53.72)$ & $22(10.57)$ & $42(20.19)$ & $1(0.48)$ \\
\hline Muscles weakness & $45(37.19)$ & $23(11.06)$ & $18(8.65)$ & $2(0.96)$ \\
\hline
\end{tabular}

ADR: Adverse drug reactions, CTCAE: Common terminology criteria for adverse events 
and hypertension+diabetes mellitus+asthma had no association with neurotoxicity. In contrast to Zhang's et al. research which states that comorbidities can increase the incidence of ADRs due to cardiac insufficiency, lung, kidney, and liver damage can cause changes in pharmacokinetics or pharmacodynamics [20]. A study of 157 patients undergoing chemotherapy showed that smoking, consuming alcohol, having an age of $>70$ years, and being overweight were at high risk for increasing the incidence of ADRs [21].

\section{CONCLUSION}

The incidences of ADRs in patients using carboplatin-paclitaxel therapy regimen in this study were peripheral neuropathy sensory $(77.69 \%)$; peripheral neuropathy motoric (3.31\%); arthralgia (53.72\%); and muscle weakness $(37.19 \%)$ The instrument to measure the severity in this study used CTCAE with the results of ADRs with grade 1 (35.08\%), grade $2(61.02)$, grade $3(2.88 \%)$, and at grades 4 and $5(0 \%)$. Risk factors gender, age, length of stay, type of cancer, number of cycles, and comorbidities has not affected the incidence of neurotoxicity in patients with carboplatin-paclitaxel therapy. This study expected can anticipate side effects during the treatment period to increase the effectiveness of therapy and the quality of life of patients.

\section{ACKNOWLEDGMENT}

The authors thank to Dr. Moewardi Hospital Surakarta for allowing and facilitating authors in data collection.

\section{AUTHOR'S CONTRIBUTIONS}

Annisa Diyan Meitasari and Em Sutrisna discussed the study conception and design. Annisa Diyan Meitasari survey ADRs patients, data collection, and analysis. All authors discussed the final manuscript.

\section{CONFLICT OF INTEREST}

All authors stated no potential conflict of interest with research, authorship, and publication of this article.

\section{AUTHORS FUNDING}

Any grant sources did not fund this research.

\section{REFERENCES}

1. Canadian association of pharmacy in oncology. Oncol Basics Oncol Pract Essent 2005;20:52-8.

2. World Health Organization. Latest Global Cancer Data. Geneva: World Health Organization; 2018.

3. Singh S, Dhasmana DC, Singh PK. Pattern of adverse drug reactions to anticancer drugs: A quantitative and qualitative analysis. Indian J Med
Paediatr Oncol 2017;38:140-5.

4. BC Cancer Agency. CRBPPACL (Carboplatin-Paclitaxel) Regimen. Canada: BC Cancer Agency; 2019.

5. Akin JM, Waddell JA, Solimando DA. Paclitaxel and carboplatin (TC) regimen for ovarian cancer. Hosp Pharm 2014;49:425-31.

6. Aberg L, Lacy C, Goldman M, Lance L. Drug Information Handbook. $17^{\text {th }}$ ed. United States: Lexycomp; 2009.

7. Indrayathi PA, Noviyani R, Niruri R, Budiana IN, Tunas K. Difference in blood function toxicity between stadium IIB-IIIB squamous cell cervical cancer patients with paclitaxel cisplatin and paclitaxel carboplatin chemotherapy at Sanglah hospital, Denpasar. Asian J Pharm Clin Res 2018;11:224-7.

8. Thapaliya K, Shrestha A, Prajapati S, Subedi R, Giri S. Study of pattern of adverse drug reaction due to cancer chemotherapy and their management in hospitalized patient in BP Koirala memorial cancer hospital. J Chitwan Med Coll 2014;4:24-8.

9. Schatz BS, Pharm D, Weber RJ, Pharm D. Adverse Drug Reactions. United States: American Collage of Clinical Pharmacy; 2015.

10. Fountzilas BG, Bafaloukos D, Aravantinos G. Paclitaxel and carboplatin as first-line chemotherapy for advanced breast cancer. Cancer Network 1998; $12: 45-8$

11. NCCN. Cervical Cancer Treatment Regimens. Cancer Therapy Advisor. United States: NCCN; 2019. p. 1-8

12. Fotopoulou C. Limitations to the use of carboplatin-based therapy in advanced ovarian cancer. Eur J Cancer Suppl 2014;12:13-6.

13. Kolek V. Advantages and disadvantages of Cisplatin or carboplatin in adjuvant chemotherapy of NSCLC. Transl Lung Cancer Res 2014;3:7.

14. Kumar S, Badruddeen B, Singh SP, Khan MI. A prospective study of adverse drug reactions due to platinum analogs-chemotherapy in a tertiary care hospital. Asian J Pharm Clin Res 2018;11:215-8.

15. Kim JW, Lee Y, Hwang IG, Song HS, Koh SJ, Ko YH, et al. Predicting cumulative incidence of adverse events in older patients with cancer undergoing first-line palliative chemotherapy: Korean cancer study group (KCSG) multicentre prospective study. Br J Cancer 2018;118:1169-75.

16. Staff NP, Grisold A, Grisold W, Windebank AJ, Clinic M. Chemotherapy induced peripheral neuropathy-current review. Ann Neurol 2018;81:772-81.

17. Saini VK, Sewal RK, Ahmad Y, Medhi B. Prospective observational study of adverse drug reactions of anticancer drugs used in cancer treatment in a tertiary care hospital. Indian J Pharm Sci 2015;77:687- 93.

18. Wang F, Du X, Li X, Liu N, Yu H, Sheng X. Effects of sequential paclitaxel-carboplatin followed by gemcitabine-based chemotherapy compared with paclitaxel-carboplatin therapy administered to patients with advanced epithelial ovarian cancer. Medicine 2016;95:1-7.

19. Shrestha S, Shakya R, Shrestha S, Shakya S. Adverse drug reaction due to cancer chemotherapy and its financial burden in different hospitals of Nepal. Int J Pharmacovig 2017;2:1-7.

20. Zhang M, Price SD, Sanfilippo FM, Preen DB, Bulsara MK. Comorbidity and repeat admission to hospital for adverse drug reactions in older adults: Retrospective cohort study. BMJ Open 2009:338:1-21.

21. Sneha SG, Simhadri K, Subeesh VK, Sneha SV. Predictors of adverse drug reactions in geriatric patients: An exploratory study among cancer patients. South Asian J Cancer 2019;8:130-3. 